\title{
Infectious diseases - sometimes out of sight, never out of mind
}

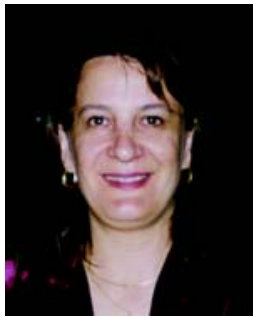

Tania Janusic Deputy Editor mja@mja.com.au

doi: 10.5694/mjal4.c0317

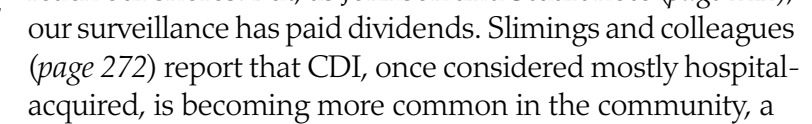
acquired, is becoming more common in the community, a finding similar to overseas trends.

Surveillance and vigilance are essential, although not always successful. Worth and colleagues (page 282) show that continuous surveillance for Staphylococcus aureus bloodstream infection in Victorian hospitals has been effective, whereas Gunaratnam and colleagues (page 290) found that screening for pandemic (H1N1) 2009 influenza at Sydney International Airport was not effective in detecting cases.

The association between risky behaviour, such as sharing needles, and bloodborne infections is well established. Reekie and colleagues (page 277) report encouragingly on new prison entrants participating in the National Prison Entrants' Bloodborne Virus Survey. Although half the participants reported injecting drug use, there was a very low prevalence of $\mathrm{HIV}$, which may be due to harm minimisation programs such as access to clean needles and methadone. The most prevalent bloodborne virus was hepatitis $\mathrm{C}$, but a third of those testing positive for this were unaware of their infection status.

Weakened human defences open the gate for unpleasant organisms such as Listeria monocytogenes, named after the pioneer of sterile surgery, Joseph Lister. L. monocytogenes meningitis accounts for $5 \%-10 \%$ of bacterial meningitis and has high mortality, perhaps due to concomitant encephalitis. Its appetite is not confined to those with poor immunity; Otome and colleagues (page 259) report a case in an immunocompetent person.

We welcome reports of improvements in Indigenous health. Crowe and colleagues (page 286), working predominantly in Indigenous communities in the Northern Territory, found a decrease over 11 years in microbiologically confirmed cases of infection with Trichuris trichiura, a soil-transmitted helminth associated with poor living conditions. Deworming campaigns may have led to a reduction in the helminth egg burden. This change, when linked with better living conditions, improved sanitation and less poverty, offers hope.

In Australia, Mycobacterium ulcerans, the causative organism associated with indolent skin ulcers that complicate cuts and scratches among people living in wet conditions, was first seen in Bairnsdale, Victoria. Now, with an expanded evidence base, $\mathrm{O}^{\prime}$ Brien and colleagues update the guidelines for its management (page 267), the main change being antibiotics as first-line therapy and a shorter duration of antibiotic treatment.

After initial infection with varicella zoster virus, T cell immunity is boosted by subsequent exposure to chicken pox. However, this natural boost has been lost since 2005, as vaccination has markedly diminished the number of childhood cases. Cunningham and colleagues (page 243) discuss mechanisms and present recent evidence about the effectiveness of vaccines in preventing shingles in older age groups.

As molecular science progresses, we learn more about the intricate adaptations underpinning antimicrobial resistance. In the Asia-Pacific region, an epidemic of drugresistant tuberculosis threatens, warn Majumdar and colleagues (page 241). They advocate for an international collaboration to bring this problem under control.

Craig Venter, known for his involvement with sequencing the human genome, wrote about molecular biological approaches to preparing for the next influenza pandemic in his recent book, Life at the speed of light. The interplay of biological and informational sciences and computing is opening doors hitherto closed. But the more we learn, and to some extent the more control we gain over infections, the greater our respect for them grows. 口

\section{For love of country}

Cate Swannell Careers Editor cswannell@mja.com.au
Scottish-born Dr Carol Cox fell in love with the Australian outback during a 1975 posting with the Royal Flying Doctor Service to Mt Isa. She returned with her Aussie husband three years later and has been caring for the people of rural Queensland ever since. Based in Toowoomba, she flies from town to town, providing a consistent medical presence during one of the worst droughts in the area's history. She speaks with Cate Swannell about her life and inspirations (page C4).
Doctors should take a tip from patients and seek a second opinion when it comes to investing. But finding a financial planner who has your best interests in mind has its challenges. Take the time to find the right person or organisation and don't be afraid to put them through their paces. The adviser should know the medical industry well, as well as knowing the financial services field (page C1). 